\section{Zaykov V., Mescheryakov V., Zhuravlov Yu.}

\title{
DETERMINATION OF THE MAXIMUM COOLING CAPACITIES OF TWO-STAGE COOLERS WITH A VARIATION IN THE GEOMETRY OF BRANCHES IN STAGES
}

Розглянуто вплив геометрії гілок термоелементів в каскадах на параметри і показники надійності двокаскадних термоелектричних охолоджувачів різних конструкиій при послідовному електричному з'єднані каскадів в режимі максимального перепаду температури. Одержані співвідношення для визначення оптимальної геометрї гілок термоелементів в каскадах, що відповідає найбільшому значенню перепаду температури для різних конструкцій охолоджувачів при заданому робочому струмі.

Ключові слова: термоелектричний охолоджуючий пристрій, геометрія гілок термоелементів, максимальний перепад температури, конструкцї охолоджувачів.

\section{Introduction}

Thermoelectric cooling devices are among the most promising devices for providing thermal regimes for radio electronic equipment. This is due to the lack of moving components, small dimensions, high speed, mechanical and impact strength. The disadvantage of thermoelectric coolers (TEC) is lower cooling capacity compared to compression cooling devices, which makes research relevant to increase their cooling capacity relevant. It is obvious that the main method of increasing the TEC cooling capacity is selection of the material of the thermoelements of the branches with the maximum value of thermoelectric efficiency. However, the choice of semiconductor materials for thermoelements for industrial applications is rather limited, therefore, with the existing technology and specified materials, constructive methods are needed to increase the cooling capacity of thermoelectric coolers.

\section{The object of research and its technological audit}

The object of research is an analytical model of the relationship between the reliability of a two-stage thermoelectric cooler and the geometry of the branches of thermoelements and its cooling capabilities.

The thermoelectric cooler is parallel arranged ceramic cold and hot electrodes, between which are installed thermoelements, electrically connected in series. The existing model of a thermoelectric cooling device is based on the law of energy conservation, in particular, on the balance of heat fluxes due to the thermal conductivity between the load, cold electrode, thermoelements, hot electrode, radiator and external environment.

Thermoelectric cooling devices belong to solid-state coolers, the reliability and mass-size characteristics of which significantly exceed the compressors of this purpose up to a cooling power of $500 \mathrm{~W}$ [1]. This is especially important for heat-loaded radio-electronic airborne elements operating in a wide range of climatic and mechanical effects [2].
The spectrum of use of thermoelectric converters is wide: from systems for providing thermal regimes for electronic equipment, for medical systems for the formation of temperature fields, for household refrigerators and air conditioners to generators of electrical energy [3]. The cooling capacity of thermoelectric cooling devices, which is lower than the compressible cooling capacity, has made the problem of increasing the power parameters of the thermal power plant is urgent, since they are beyond competition by other indicators.

Another problem is reliability indicators, since modern heat-loaded elements operate under conditions close to critical. Under the appropriate conditions, thermoelectric systems also operate to ensure their thermal conditions [4]. The increased thermal load significantly worsens the reliability index of the power plant [5], therefore the design of the device by the criterion of maximum cooling capacity should be carried out taking into account this circumstance. In [6], the influence of changing the geometry of thermoelements on the reliability indicators of single-stage TEC is analyzed, however, two-stage coolers have a number of features that are mandatory [7]. The expediency of revealing the connection of reliability indicators with variation in the geometry of the branches of a stage thermoelectric cooling device is due to the potential possibility of improving the quality of two-stage coolers. At the same time, the existing technology of their manufacture remains unchanged.

\section{The aim and objectives of research}

The aim of research is revealing the relationship between the cooling capabilities and reliability indicators of a two-stage thermoelectric cooler with the geometry of the branches of thermoelements during their subsequent electrical connection.

To achieve this aim, it is necessary to solve the following tasks:

1. To develop a model for coupling the failure rate with design parameters and energy parameters of a twostage thermoelectric cooling device. 
2. To analyze the simulation results to determine the conditions for achieving the maximum temperature difference.

\section{Research of existing solutions of the problem}

Among the main directions for eliminating the problem of increasing the cooling capacity of thermoelectric cooling devices identified in the resources of the world scientific periodicals, the following can be singled out:

- creation of new materials with increased thermo-

electric efficiency [8, 9];

- use of thin-film technologies for manufacturing thermo-

element materials [10-12];

- transition to nanostructural technologies for manufacturing thermoelement materials [13-15];

- attraction of external electromagnetic fields for control of charge transfer in the thermoelement material [16]; - optimization of heat transfer in a thermoelectric device [17, 18];

- involving elements of reliability theory in the techno-

logy of manufacturing of thermoelectric coolers [19-21].

As follows from the approaches presented in the world periodicals, the main direction is the creation of new materials with higher values of thermoelectric efficiency and materials manufacturing technologies, which directly determines the cooling capacity of the thermoelectric device. At the same time, industrially used thermoelectric materials have a very limited value of thermoelectric efficiency already for half a century $[4,5]$. Control of the thermoelectric cooler parameters by electromagnetic fields significantly complicates the system of providing thermal conditions, therefore it can be recommended only in special applications.

Studies of influence of the thermoelectric coolers on operational reliability indicators are carried out either at the stage of preparation of the technology of manufacturing products, or after manufacturing [21]. This limits the possibilities of design impact on the resulting reliability indices of the thermoelectric device.

Thus, the results of the analysis allow to conclude that the determination of the relationship between the reliability indices of a thermoelectric device and the design parameters of thermoelements is actual.

\section{Methods of research}

As the methods of research let's use the methods of mathematical modeling, the theory of heat transfer and reliability, which allow to obtain analytical expressions used for analysis. From an applied point of view, this approach allows to compare design solutions and design stage thermoelectric cooling devices with priority to the reliability criterion. At the same time constructive and energy indicators that meet the requirements of the terms of reference under the existing technology are taken into account.

\section{Research results}

6.1. Development of a reliahility-oriented model. In some cases, the developer has a number of different designs of cascade thermoelectric devices (CTED). These devices can differ from each other by the number of thermocouples $n_{1}, n_{2}$ in stages (ratio $n_{1} / n_{2}$ ) and the geometry of their branches (the ratio of the height 1 of the stage branch to the area of its cross section $S$ ). There are also possible series of standard (unified) modules, on the basis of which it is possible to construct a CTED at $(l / S)_{i}=$ const or $(l / S)_{i}=$ var

In [6], the regime of the maximum temperature difference $\Delta T_{\max }$ of two-stage TECs of various designs $\left(n_{1} / n_{2}=\right.$ var $)$ at $(l / S)_{1}=(l / S)_{2}=10 \mathrm{~cm}^{-1}$ and their maximum cooling capabilities and reliability parameters are considered. Calculations of the maximum cooling capabilities, namely, the maximum temperature difference $\Delta T_{\max },(l / S)_{1}=(l / S)_{2}=$ $=40 \ldots 2.0 \mathrm{~cm}^{-1}$ and different values of $n_{1} / n_{2}$ are carried out. Analysis of the results showed that $\Delta T_{\max }$ does not depend on the geometry of the branches of thermoelements in stages, but depends on the efficiency of the initial materials.

Let's consider the estimation of cooling capabilities and reliability indicators of two-stage TEC of various designs $\left(n_{1} / n_{2}=\right.$ var $)$ at $(l / S)_{1}=\operatorname{var}=20 ; 15 ; 10 ; 4.5 \mathrm{~cm}^{-1}$ and $(l / S)_{2}=10 \mathrm{~cm}^{-1}$ for the series electrical connection of the stages.

To determine the optimal geometry of the branches of thermoelements in the first stage $(l / S)_{1 \text { opt }}$ corresponding to the largest value of the maximum temperature difference $\Delta T_{\max }$ of a two-stage TEC for a given geometry of the thermoelement branches in the second stage $(l / S)_{2}=$ const, let's use the relations [5].

The condition of thermal conjugation of stages can be written in the form:

$$
Q_{01}+W_{1}=Q_{02}
$$

where $Q_{01}=0$ for $\Delta T_{\max }$ - the TEC thermal load, W.

The power consumption of the first stage $W_{1}$ and the cooling capacity of the second stage $Q_{02}$ included in this expression are calculated by the formulas:

$$
\begin{aligned}
& W_{1}=2 n_{1}\left[I^{2} R_{1}+\bar{e}_{1} I\left(T_{1}-T_{0}\right)\right]= \\
& =2 n_{1}\left[I^{2} \frac{(l / S)_{1}}{\bar{\sigma}_{1}}+\bar{e}_{1} I\left(T_{1}-T_{0}\right)\right] \\
& Q_{02}=2 n_{2}\left[\bar{e}_{2} I T_{1}-0,5 I^{2} R_{2}-K_{2}\left(T-T_{1}\right)\right]= \\
& =-2 n_{2}\left[\bar{e}_{2} I T_{1}-\frac{0,5 I^{2}(l / S)_{2}}{\bar{\sigma}_{2}}-\frac{\bar{\chi}_{2}}{(l / S)_{2}}\left(T-T_{1}\right)\right],
\end{aligned}
$$

where $n_{1}, n_{2}$ - the number of thermocouples in stages, pieces; $I$ - the working current, A; $R_{i}$ - the electrical resistance of the branch of the thermoelement in the $i$-th stage, Ohm, $R_{i}=$ $=(l / S)_{i} / \bar{\sigma}_{i} ; \bar{e}_{i}, \bar{\sigma}_{i}, \bar{\chi}_{i}$ - respectively, the averaged values of the coefficient of thermo-emf, $\mathrm{V} / \mathrm{K}$, electrical conductivity, $\mathrm{S} / \mathrm{cm}$, and thermal conductivity, $\mathrm{W} /(\mathrm{cm} \cdot \mathrm{K})$, the branches of thermoelements in the $i$-th stage; $T_{0}$ - heat-absorbing junction temperature, $\mathrm{K} ; T_{1}$ - intermediate temperature, $\mathrm{K}$; $T$ - heat-absorbing junction temperature, K.

Let's substitute (2) and (3) into (1) and obtain an expression for the intermediate temperature:

$$
T_{1}=T_{0}\left(1+\frac{\bar{e}_{1} I}{\bar{\chi}_{1}}(l / S)_{1}\right)-0,5 I^{2} \frac{(l / S)_{1}^{2}}{\bar{\sigma}_{1} \bar{\chi}_{1}} .
$$

Substituting (2)-(4) in (1), obtain an expression for determining the heat-absorbing junction temperature: 


$$
\begin{aligned}
& T_{0}=\frac{1}{\bar{e}_{2} I+\frac{\bar{\chi}_{2}}{(l / S)_{2}}+I \frac{\bar{e}_{1}(l / S)_{1}}{\bar{\chi}_{1}}\left(\bar{e}_{2} I+\frac{\bar{\chi}_{2}}{(l / S)_{2}}\right)-I^{2} \frac{n_{1}}{n_{2}} \frac{\bar{e}_{1}^{2}(l / S)_{1}}{\bar{\chi}_{1}}} \times \\
& \times\left[\frac{\bar{\chi}_{2}}{(l / S)_{2}} T+0.5 I^{2} \frac{(l / S)_{1}^{2}}{\bar{\sigma}_{1} \bar{\chi}_{1}}\left(\bar{e}_{2} I+\frac{\bar{\chi}_{2}}{(l / S)_{2}}\right)+0.5 I^{2} \frac{(l / S)_{2}}{\bar{\sigma}_{2}}+\right. \\
& \left.+I^{2} \frac{n_{1}}{n_{2}} \frac{(l / S)_{1}}{\bar{\sigma}_{1}}-0.5 I^{3} \frac{n_{1}}{n_{2}} \frac{\bar{e}_{1}(l / S)_{1}^{2}}{\bar{\sigma}_{1} \bar{\chi}_{1}}\right] .
\end{aligned}
$$

Let's introduce the following notation:

$$
\begin{aligned}
& A=\frac{\bar{\chi}_{2}}{(l / S)_{2}} T ; \quad B=0.5 I^{2} \frac{1}{\bar{\sigma}_{1} \bar{\chi}_{1}} ; \quad f=\bar{e}_{2} I+\frac{\bar{\chi}_{2}}{(l / S)_{2}} ; \\
& C=0.5 I^{2} \frac{(l / S)_{2}}{\bar{\sigma}_{2}} ; \quad D=I^{2} \frac{n_{1}}{n_{2} \bar{\sigma}_{1}} ; \\
& E=0.5 I^{3} \frac{n_{1}}{n_{2}} \frac{\bar{e}_{1}}{\sigma_{1} \bar{\chi}_{1}} ; \quad p=I \frac{\bar{e}_{1}}{\bar{\chi}_{1}} ; \quad K=I^{2} \frac{n_{1}}{n_{2}} \frac{\bar{e}_{1}^{2}}{\bar{\chi}_{1}} .
\end{aligned}
$$

Taking this into account, expression (5) takes the form:

$$
T_{0}=\frac{A+B f(l / S)_{1}^{2}+C+D(l / S)_{1}-E(l / S)_{1}^{2}}{f+(l / S)_{1}(p f-K)} .
$$

From condition $\frac{d T_{0}}{d(l / S)_{1}}=0$ :

$$
\begin{aligned}
& (l / S)_{1 \text { opt }}=\frac{f}{p f-K} \times \\
& \times\left(\sqrt{1-\frac{D(p f-K)}{(B f-E) f}+\frac{(A+C)(p f-K)^{2}}{(B f-E) f^{2}}}-1\right) .
\end{aligned}
$$

The failure rate $\lambda / \lambda_{0}$ of a two-stage TEC can be determined from the expression:

$$
\begin{aligned}
& \frac{\lambda}{\lambda_{0}}=n_{1} B_{1}^{2}\left(\Theta_{1}+C_{1}\right)\left(\frac{B_{1}+\frac{\Delta T_{\max 1}}{T_{0}} \Theta_{1}}{1+\frac{\Delta T_{\max 1}}{T_{0}} \Theta_{1}}\right)^{2} K_{T 1}+ \\
& +n_{2} B_{2}^{2}\left(\Theta_{2}+C_{2}\right)\left(\frac{B_{2}+\frac{\Delta T_{\max 2}}{T_{1}} \Theta_{2}}{1+\frac{\Delta T_{\max 2}}{T_{1}} \Theta_{2}}\right)^{2} K_{T 2},
\end{aligned}
$$

where $\Theta_{i}$ - the relative temperature drop in the $i$-th stage, $\Theta_{1}=\left(T_{1}-T_{0}\right) / \Delta T_{\max 1}, \Theta_{2}=\left(T-T_{1}\right) / \Delta T_{\max 2} ; \Delta T_{\max i}-$ the maximum temperature drop in the $i$-th stage, $\mathrm{K}, \Delta T_{\max i}=0.5 \bar{z}_{i} T_{i-1}^{2}$; $C_{i}$ - relative thermal load in the $i$-th stage, $C_{1}=\frac{Q_{01}}{n_{1} I_{\max 1}^{2} R_{1}}$, $C_{2}=\frac{W_{1}+Q_{01}}{n_{2} I_{\max 2}^{2} R_{2}} ; B_{i}-$ the relative operating current in the $i$-th stage, $B_{i}=I / I_{\max i} ; I_{\max i}$ - the maximum operating current in the $i$-th stage, A, $I_{\max i}=\bar{e}_{i} T_{i-1} / R_{i} ; \bar{z}_{i}$ - the average value of the material efficiency of the branches of the thermocouples of the $i$-th stage, $1 / \mathrm{K} ; K_{T i}$ - a significance factor that takes into account the effect of a lowered temperature in the $i$-th stage.

The probability of failure-free operation $P$ of a two-stage TEC can be determined from the expression:

$P=\exp (-\lambda t)$

where $t$ is the assigned resource, h.

The voltage drop of a two-stage TEC can be determined from the expression:

$U_{\Sigma}=W_{\Sigma} / I$

Expressions are the basis for calculating the parameters and reliability indicators of a two-stage cooler.

6.2. Analysis of the developed reliability-oriented model. The calculation of the main parameters and reliability indices is carried out for various designs of a two-stage TEC $\left(n_{2} / n_{2}=\right.$ var $)$ with a fixed number of thermocouples in the second stage $n_{2}=27$, the optimum value $(l / S)_{1}$ and $(l / S)_{2}=10 \mathrm{~cm}^{-1}$. To find the optimal geometry of the branches of the first-stage $(l / S)_{1 \text { opt }}$ thermoelements, let's use a parameter that takes into account the geometry of the branches in two stages:

$$
a=\frac{(l / S)_{1}}{(l / S)_{2}} .
$$

The results of the calculations are given in Table 1 and in Fig. 1-6.

Analysis of the calculated data shows that for fixed values of the parameter a with a decrease in the ratio $n_{1} / n_{2}$ :

- the intermediate temperature $T_{1}$ decreases (Fig. 1);

- the relative operating current in the stages $B_{1}$ and

$B_{2}$ increases (Fig. 2);

- the relative temperature drop in the first stage $\Theta_{1}$ increases for $a=0.45$ and $a=1.0$ and decreases, passing through a maximum for $a=1.5$ and $a=2.0$ (Fig. 3, $a$ ). In the second stage, $\Theta_{2}$ increases for different values of a (Fig. 3, b);

- the value of the operating current I increases (Fig. 4);

- the optimal value of the geometry parameter of the branches of thermoelements $a_{\text {opt }}$ decreases, passing through a minimum at $n_{1} / n_{2}=0.5$ (Fig. 4);

- the maximum temperature difference $\Delta T_{\max }$ increases (Fig. 5);

- the failure rate $\lambda / \lambda_{0}$ increases (Fig. 6, $a$ ) due to the growth of the relative operating currents $B_{1}$ and $B_{2}$, as well as the growth of relative temperature differences $\Theta_{1}$ and $\Theta_{2}$;

- the probability of failure-free operation $P$ decreases (Fig. 6, b).

Analysis of the calculated data showed that for fixed values of the ratio $n_{1} / n_{2}$ with increasing parameter $a$ :

- the intermediate temperature $T_{1}$ increases (Fig. 1); - the relative operating current of the first stage $B_{1}$ increases, and the second stage $B_{2}$ slightly decreases (Fig. 2);

- the relative temperature drop in the second stage $\Theta_{2}$ increases (Fig. 3, b);

- the probability of failure-free operation $P$ decreases (Fig. 6, b). 
The main parameters and reliability indices of a two-stage thermoelectric cooler at $T=300 \mathrm{~K}, Q_{0}=1.0 \mathrm{~W}, \bar{z}_{\mathrm{m}}=2,4 \cdot 10^{-3} 1 / \mathrm{K}$, $n_{2}=27,(1 / 5)_{2}=10 \mathrm{~cm}^{-1}$ and variation of parameter a for different values of $n_{1} / \Pi_{2}$ in the $\Delta T_{\max }$ mode

\begin{tabular}{|c|c|c|c|c|c|c|c|c|c|c|c|c|c|c|c|c|c|}
\hline $\begin{array}{c}\text { Design } \\
\text { (modules } \\
\text { in cascades } \\
\text { (stages)) }\end{array}$ & $a$ & $\begin{array}{c}R_{1} \cdot 10^{3} \\
\Omega\end{array}$ & $\begin{array}{c}R_{2} \cdot 10^{3}, \\
\Omega\end{array}$ & $\underset{\mathrm{A}}{I_{\max 1}}$ & $\begin{array}{l}I_{\max 2 \prime} \\
\mathrm{A}\end{array}$ & $B_{1}$ & $B_{2}$ & $\Theta_{1}$ & $\Theta_{2}$ & $T_{1}, \mathrm{~K}$ & $\Delta T_{\max }$ & $\begin{array}{l}W_{\Sigma \prime} \\
\mathrm{BT}\end{array}$ & $\begin{array}{l}U_{\Sigma \prime} \\
\mathrm{B}\end{array}$ & $(1 / 5)_{1}$ & $\lambda / \lambda_{0}$ & $\begin{array}{c}\lambda \cdot 10^{8} \\
1 / \mathrm{h}\end{array}$ & $P$ \\
\hline \multicolumn{18}{|c|}{$n_{1} / n_{2}=1.0 ; n_{1}=27 ; I=2 \mathrm{~A}$} \\
\hline $\begin{array}{c}\text { M4.5-27/ } \\
\text { M10-27 }\end{array}$ & 0.45 & 3.88 & 10.1 & 1.11 & 5.02 & 0.18 & 0.40 & 0.33 & 0.48 & 261.0 & 59.6 & 3.87 & 1.94 & 4.5 & 0.63 & 1.89 & 0.99981 \\
\hline $\begin{array}{l}\text { M10-27/ } \\
\text { M10-27 }\end{array}$ & 1.0 & 9.43 & 10.53 & 4.7 & 5.25 & 0.43 & 0.380 & 0.67 & 0.23 & 279.0 & 64.0 & 5.63 & 2.82 & 10 & 1.33 & 4.0 & 0.99960 \\
\hline $\begin{array}{c}\text { M13.8-27/ } \\
\text { M10-27 }\end{array}$ & 1.38 & 12.1 & 10.42 & 3.51 & 5.38 & 0.57 & 0.372 & 0.825 & 0.174 & 283.3 & 66.6 & 6.23 & 3.11 & 13.8 & 3.52 & 10.6 & 0.99894 \\
\hline $\begin{array}{c}\text { M15-27/ } \\
\text { M10-27 }\end{array}$ & 1.5 & 13.9 & 10.64 & 3.13 & 5.41 & 0.64 & 0.37 & 0.87 & 0.124 & 287.7 & 66.1 & 6.64 & 3.33 & 15 & 5.38 & 16.1 & 0.9984 \\
\hline $\begin{array}{l}\text { M20-27/ } \\
\text { M10-27 }\end{array}$ & 2.0 & 18.9 & 11.1 & 2.37 & 5.40 & 0.84 & 0.37 & 0.95 & 0.0 & 300 & 62.2 & 9.75 & 4.9 & 20 & 14.7 & 44.2 & 0.9956 \\
\hline \multicolumn{18}{|c|}{$n_{1} / n_{2}=0.67 ; n_{1}=18 ; I=2.6 \mathrm{~A}$} \\
\hline $\begin{array}{c}\text { M4.5-18/ } \\
\text { M10-27 }\end{array}$ & 0.45 & 3.81 & 10.0 & 10.6 & 4.97 & 0.245 & 0.523 & 0.43 & 0.57 & 255.9 & 68.7 & 6.2 & 2.4 & 4.5 & 2.11 & 6.32 & 0.99937 \\
\hline $\begin{array}{c}\text { M10-18/ } \\
\text { M10-27 }\end{array}$ & 1.0 & 8.47 & 10.42 & 4.65 & 5.06 & 0.56 & 0.51 & 0.80 & 0.36 & 269.0 & 74.7 & 7.43 & 2.86 & 10 & 3.56 & 10.7 & 0.99893 \\
\hline $\begin{array}{c}\text { M11.3-18/ } \\
\text { M10-27 }\end{array}$ & 1.13 & 9.58 & 10.42 & 4.1 & 5.04 & 0.634 & 0.516 & 0.81 & 0.38 & 267.7 & 75.7 & 7.73 & 3.0 & 11.3 & 4.85 & 14.55 & 0.99855 \\
\hline $\begin{array}{l}\text { M15-18/ } \\
\text { M10-27 }\end{array}$ & 1.5 & 12.9 & 10.42 & 3.14 & 5.27 & 0.83 & 0.49 & 0.980 & 0.226 & 279.0 & 75.3 & 8.43 & 3.24 & 15 & 10.9 & 32.6 & 0.9967 \\
\hline $\begin{array}{l}\text { M20-18/ } \\
\text { M10-27 }\end{array}$ & 2.0 & 18.2 & 10.9 & 2.36 & 5.35 & 1.10 & 0.49 & 0.987 & 0.084 & 291.4 & 68.6 & 9.70 & 3.72 & 20 & 27.3 & 82.0 & 0.99183 \\
\hline \multicolumn{18}{|c|}{$n_{1} / n_{2}=0.50 ; n_{1}=13.5 ; I=3.1 \mathrm{~A}$} \\
\hline $\begin{array}{c}\text { M4.5-13.5/ } \\
\text { M10-27 }\end{array}$ & 0.45 & 3.69 & 9.8 & 10.47 & 4.95 & 0.30 & 0.63 & 0.50 & 0.656 & 251.3 & 75.4 & 8.0 & 2.6 & 4.5 & 4.58 & 13.75 & 0.99862 \\
\hline $\begin{array}{c}\text { M9.5-13.5/ } \\
\text { M10-27 }\end{array}$ & 0.95 & 7.8 & 10.1 & 4.83 & 5.11 & 0.64 & 0.61 & 0.91 & 0.44 & 263.5 & 82.4 & 9.1 & 2.95 & 9.5 & 6.27 & 18.8 & 0.99812 \\
\hline $\begin{array}{c}\text { M10-13.5/ } \\
\text { M10-27 }\end{array}$ & 1.0 & 8.20 & 10.1 & 4.6 & 5.10 & 0.67 & 0.61 & 0.895 & 0.455 & 262.8 & 82.2 & 9.2 & 3.0 & 10 & 6.75 & 20.2 & 0.9980 \\
\hline $\begin{array}{c}\text { M15-13.5/ } \\
\text { M10-27 }\end{array}$ & 1.5 & 12.1 & 10.1 & 3.1 & 5.3 & 1.0 & 0.59 & 1.0 & 0.32 & 272 & 79.0 & 10.0 & 3.25 & 15 & 17.25 & 51.8 & 0.99483 \\
\hline $\begin{array}{c}\text { M20-13.5/ } \\
\text { M10-27 } \\
\end{array}$ & 2.0 & 17.9 & 10.5 & 2.37 & 5.4 & 1.31 & 0.575 & 0.93 & 0.135 & 286.7 & 69.0 & 11.4 & 3.67 & 20 & 37.5 & 112.6 & 0.9988 \\
\hline \multicolumn{18}{|c|}{$n_{1} / n_{2}=0.33 ; n_{1}=9 ; I=3.3 \mathrm{~A}$} \\
\hline $\begin{array}{l}\text { M4.5-9/ } \\
\text { M10-27 }\end{array}$ & 0.45 & 3.46 & 9.62 & 10.67 & 4.88 & 0.31 & 0.68 & 0.524 & 0.744 & 247.1 & 78.9 & 8.4 & 2.54 & 4.5 & 6.32 & 19.0 & 0.99810 \\
\hline $\begin{array}{l}\text { M10-9/ } \\
\text { M10-27 }\end{array}$ & 1.0 & 7.69 & 10.0 & 4.61 & 4.94 & 0.72 & 0.668 & 0.924 & 0.594 & 254.7 & 87.6 & 9.4 & 2.84 & 10 & 10.8 & 32.5 & 0.9968 \\
\hline $\begin{array}{l}\text { M11-9/ } \\
\text { M10-27 }\end{array}$ & 1.11 & 8.54 & 10.0 & 4.14 & 4.93 & 0.80 & 0.67 & 0.925 & 0.61 & 254.0 & 88.1 & 9.56 & 2.83 & 11.1 & 9.85 & 29.6 & 0.99705 \\
\hline $\begin{array}{l}\text { M15-9/ } \\
\text { M10-27 }\end{array}$ & 1.5 & 1.1 & 10.0 & 3.03 & 5.09 & 1.09 & 0.648 & 1.0 & 0.485 & 261 & 86.8 & 10.1 & 3.07 & 15 & 18.1 & 54.2 & 0.9946 \\
\hline $\begin{array}{l}\text { M20-9/ } \\
\text { M10-27 }\end{array}$ & 2.0 & 17.0 & 10.0 & 2.3 & 5.20 & 1.43 & 0.635 & 0.81 & 0.41 & 265.6 & 77.3 & 10.9 & 3.30 & 20 & 33.4 & 100 & 0.9900 \\
\hline \multicolumn{18}{|c|}{$n_{1} / \Pi_{2}=0.20 ; n_{1}=5 ; I=3.8 \mathrm{~A}$} \\
\hline $\begin{array}{l}\text { M4.5-5/ } \\
\text { M10-27 }\end{array}$ & 0.45 & 3.40 & 9.52 & 10.1 & 4.85 & 0.38 & 0.78 & 0.61 & 0.835 & 243 & 84.6 & 10.3 & 2.71 & 4.5 & 10.9 & 32.7 & 0.9967 \\
\hline $\begin{array}{c}\text { M9.99-5/ } \\
\text { M10-27 }\end{array}$ & 0.993 & 7.64 & 9.62 & 4.39 & 4.91 & 0.86 & 0.77 & 0.984 & 0.71 & 248.7 & 95.5 & 10.9 & 2.86 & 9.93 & 13.2 & 39.6 & 0.9960 \\
\hline $\begin{array}{l}\text { M10-5/ } \\
\text { M10-27 } \\
\end{array}$ & 1.0 & 7.69 & 9.62 & 4.41 & 4.92 & 0.86 & 0.77 & 0.98 & 0.71 & 248.7 & 93.4 & 10.9 & 2.86 & 10 & 13.2 & 39.6 & 0.9960 \\
\hline $\begin{array}{l}\text { M15-5/ } \\
\text { M10-27 }\end{array}$ & 1.5 & 11.5 & 10.0 & 3.04 & 4.89 & 1.25 & 0.78 & 0.94 & 0.64 & 252 & 90.0 & 11.6 & 3.06 & 15 & 21.9 & 65.7 & 0.9935 \\
\hline $\begin{array}{l}\text { M20-5/ } \\
\text { M10-27 }\end{array}$ & 2.0 & 16.1 & 10.0 & 2.39 & 5.03 & 1.59 & 0.755 & 0.66 & 0.535 & 258 & 76.6 & 12.0 & 3.16 & 20 & 29.0 & 86.9 & 0.99135 \\
\hline \multicolumn{18}{|c|}{$n_{1} / n_{2}=0.1 ; n_{1}=3 ; I=4 \mathrm{~A}$} \\
\hline $\begin{array}{l}\text { M4.5-3/ } \\
\text { M10-27 }\end{array}$ & 0.45 & 3.40 & 9.52 & 9.97 & 4.79 & 0.40 & 0.835 & 0.637 & 0.90 & 240 & 88.1 & 11.1 & 2.78 & 4.5 & 14.4 & 43.2 & 0.9957 \\
\hline $\begin{array}{c}\text { M9.99-3/ } \\
\text { M10-27 }\end{array}$ & 1.0 & 7.52 & 9.52 & 4.32 & 4.85 & 0.926 & 0.825 & 0.99 & 0.83 & 243.1 & 96.9 & 11.4 & 2.86 & 9.997 & 15.9 & 47.7 & 0.99524 \\
\hline $\begin{array}{l}\text { M10-3/ } \\
\text { M10-27 }\end{array}$ & 1.0 & 7.52 & 9.52 & 4.32 & 4.85 & 0.926 & 0.825 & 0.99 & 0.83 & 243 & 96.8 & 11.4 & 2.86 & 10 & 15.9 & 47.7 & 0.9952 \\
\hline $\begin{array}{l}\text { M15-3/ } \\
\text { M10-27 }\end{array}$ & 1.5 & 11.3 & 9.52 & 2.96 & 4.91 & 1.35 & 0.815 & 0.875 & 0.769 & 246 & 91.2 & 11.6 & 2.91 & 15 & 21.5 & 64.4 & 0.9936 \\
\hline $\begin{array}{l}\text { M20-3/ } \\
\text { M10-27 }\end{array}$ & 2.0 & 15.9 & 9.62 & 2.35 & 4.91 & 1.70 & 0.815 & 0.51 & 0.71 & 248.7 & 77.3 & 12.0 & 3.0 & 20 & 25.2 & 75.5 & 0.9925 \\
\hline
\end{tabular}




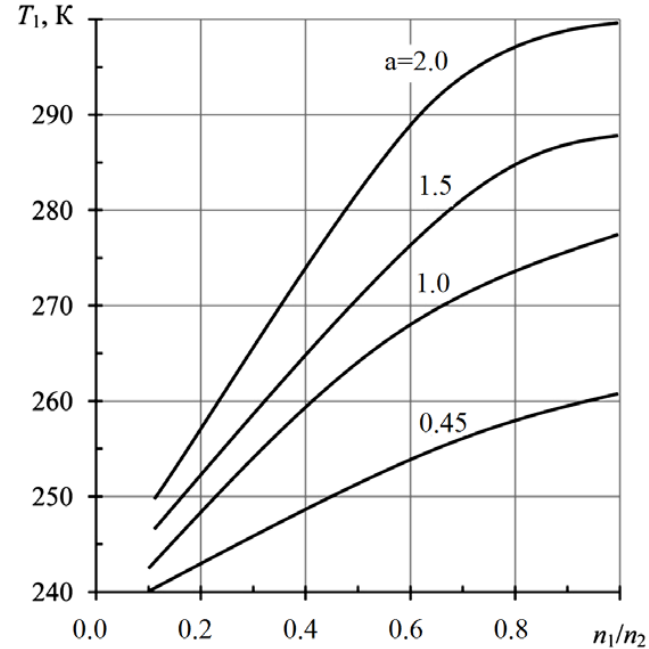

Fig. 1. Dependence of the intermediate temperature $T_{1}$ of a two-stage thermoelectric cooler on the ratio $n_{1} / n_{2}$ for different values of the parameter a at $T=300 \mathrm{~K} ;(1 / S)_{2}=10 \mathrm{~cm}^{-1} ; \Pi_{2}=27$ in the $\Delta T_{\max }$ mode
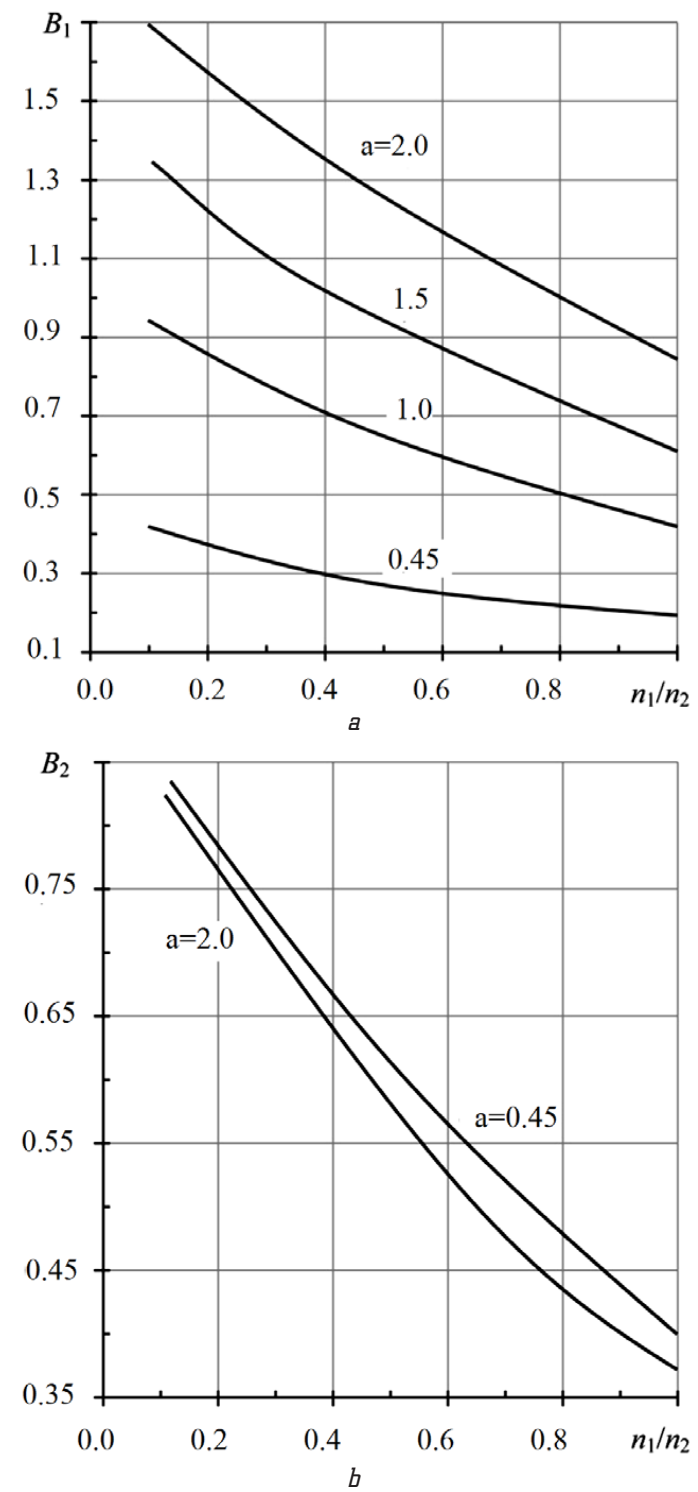

Fig. 2. Dependence of the relative operating current of cascades (stages) of a two-stage thermoelectric cooler on the ratio $n_{1} / n_{2}$ for different values of the parameter a at $T=300 \mathrm{~K} ;(1 / S)_{2}=10 \mathrm{~cm}^{-1} ; n_{2}=27$ in the $\Delta T_{\max }$ mode: $a$ - the first stage $B_{1} ; b$ - the second stage $B_{2}$
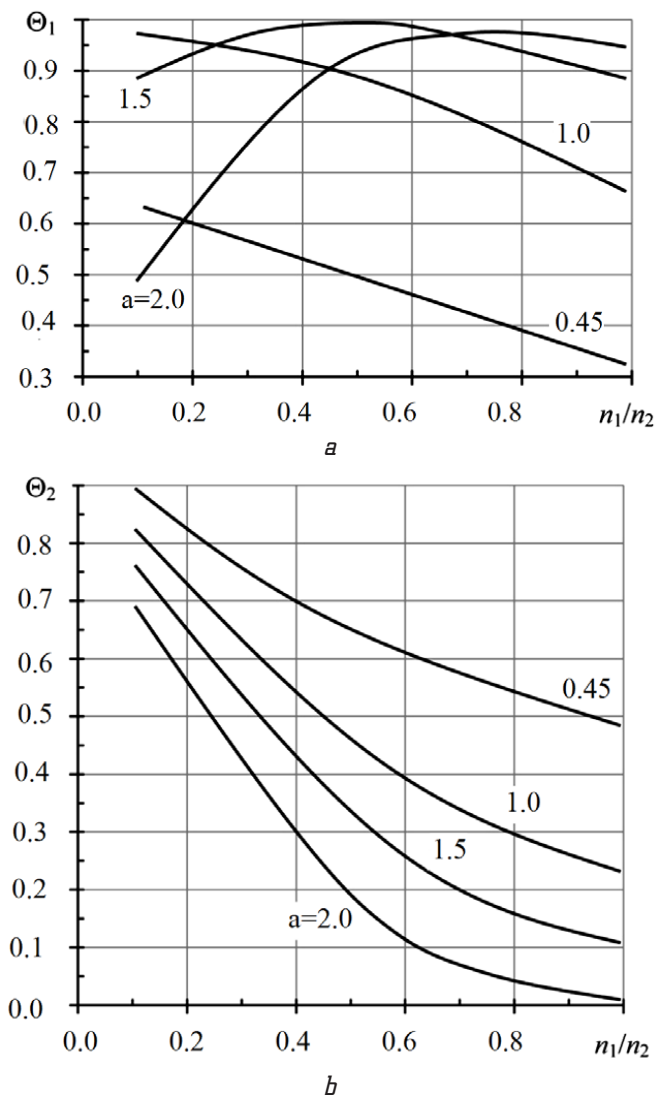

Fig. 3. Dependence of the temperature drop difference of cascades (stages) of a two-stage thermoelectric cooler on the ratio $n_{1} / n_{2}$ for different values of the parameter $a$ at $T=300 \mathrm{~K} ;(1 / S)_{2}=10 \mathrm{~cm}^{-1} ; n_{2}=27$ in the $\Delta T_{\max }$ mode: $a$ - the first stage $\Theta_{1} ; b$ - the second stage $\Theta_{2}$

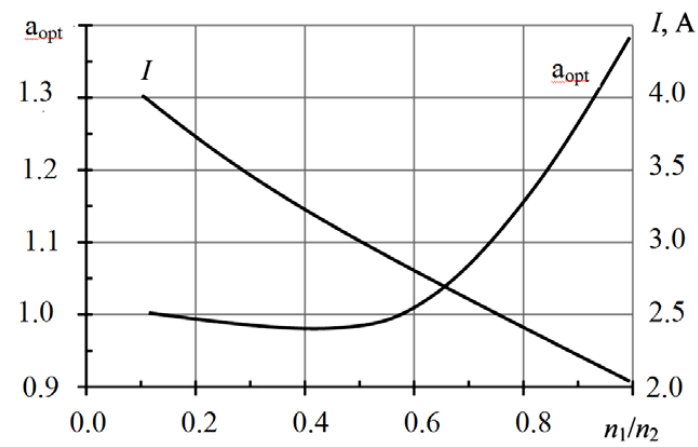

Fig. 4. Dependence of the optimum value of the parameter a corresponding to the largest value of the temperature drop: the vertex geometry parameter $a$ and the working current $I$ of the two-stage thermoelectric cooler on the ratio $\Pi_{1} / \Pi_{2}$ at $T=300 \mathrm{~K} ;(1 / 5)_{2}=10 \mathrm{~cm}^{-1}$; $n_{2}=27$ in the $\Delta T_{\max }$ mode

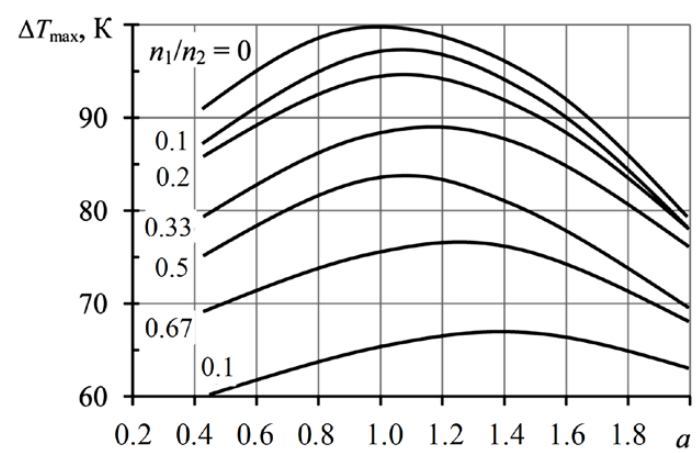

Fig. 5. Dependence of the maximum temperature difference $\Delta T_{\max }$ of a two-stage thermoelectric cooler on the parameter a for different values of the ratio $n_{1} / n_{2}$ at $T=300 \mathrm{~K} ;(1 / S)_{2}=10 \mathrm{~cm}^{-1} ; n_{2}=27$ in the $\Delta T_{\max }$ mode 

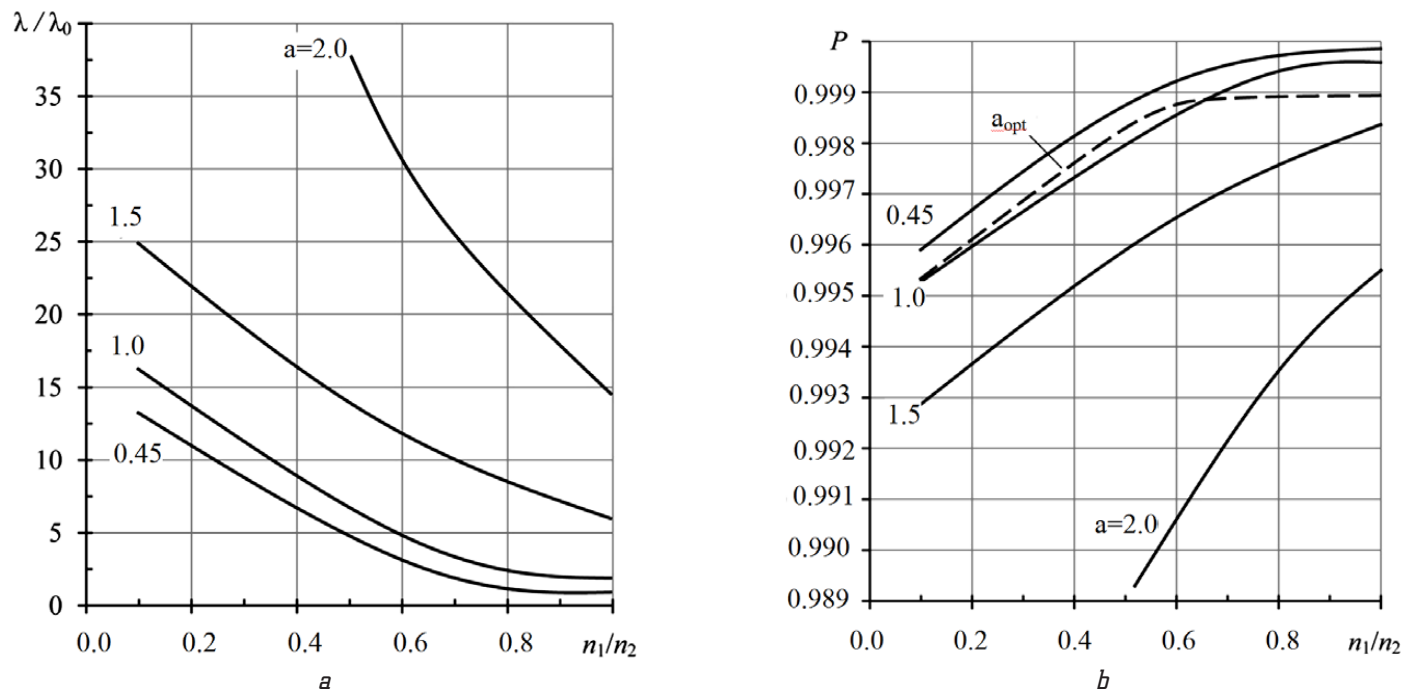

Fig. 6. Dependence of the relative failure rate $\lambda / \lambda_{0}$ and the probability of failure-free operation $P$ of a two-stage thermoelectric cooling device on the ratio $n_{1} / n_{2}$ for different values of the parameter a at $T=300 \mathrm{~K} ;(1 / 5)_{2}=10 \mathrm{~cm}^{-1} ; n_{2}=27$ in the $\Delta T_{\text {max }}$ mode: $a$ - relative failure $\lambda / \lambda_{0} ; b$ - probability of failure-free operation $P$

As can be seen from Fig. 5, the functional dependence $\Delta T_{\max }=f(a)$ for different values of the ratio $n_{1} / n_{2}$ has a pronounced maximum for a given value of the operating current $I$. For each value of the ratio $n_{1} / n_{2}$, it is possible to determine the optimal geometry of the branches of the thermoelements $a_{o p t}=(l / S)_{1} /(l / S)_{2}$, corresponding to the largest value of the maximum temperature difference $\Delta T_{\max }$. It should be noted that as the ratio $n_{1} / n_{2}$ grows, the parameter $a_{\text {opt }}$ shifts towards higher values from the traditional $a=1$ (when $\left.(l / S)_{1}=(l / S)_{2}=10\right)$.

The results of calculating the maximum temperature difference $\Delta T_{\max }$ for $a_{\text {opt }}\left(\Delta T_{\max } a_{o p t}\right)$ and for $a=1\left(\Delta T_{\max a=1}\right)$ are given in Table 2 .

Table 2

The results of calculating the maximum temperature difference

\begin{tabular}{|c|c|c|c|c|}
\hline$\Pi_{1} / \Pi_{2}$ & $A_{\text {opt }}$ & $\Delta T_{\max a \mathrm{apt}}$ & $\Delta T_{\max a=1}$ & $\gamma=\Delta T_{\max a \mathrm{apt}} / \Delta T_{\max a=1}$ \\
\hline 1.0 & 1.38 & 66.6 & 64.0 & 1.041 \\
\hline 0.67 & 1.13 & 75.7 & 74.7 & 1.01 \\
\hline 0.50 & 0.95 & 82.4 & 82.2 & 1.0024 \\
\hline 0.33 & 1.11 & 88.1 & 87.6 & 1.005 \\
\hline 0.20 & 0.993 & 95.5 & 93.4 & 1.022 \\
\hline 0.11 & 1.0 & 96.9 & 96.8 & 1.001 \\
\hline 0.0 & 1.0 & 100 & 100 & 1.0 \\
\hline
\end{tabular}

As follows from the last column of Table 2, the gain depends on the ratio of the number of thermoelements in the cascades (stages) and reaches a maximum at a ratio of thermoelements equal to unity.

\section{SWOT analysis if research results}

Strengths. The strength of this research is the justification of the possibility of increasing the reliability of two-stage thermoelectric cooling devices to $4 \%$ without improving the existing technology of industrial production and changing the material of thermocouples. From an applied point of view, this makes it possible to maintain the technical operating conditions for climatic, mechanical and radiation indicators of manufactured products unchanged with an increase in their qualitative characteristics.

Weaknesses. The weak side of this research is the fact that the proposed model takes into account a limited number of influencing factors, in particular, the thermal deformations do not take into account that occur at the junction of thermoelements with heat-removing ceramic electrodes. In cascade thermoelectric coolers, the temperature conditions for the functioning of thermocouples in cascades (stages) differ, which may affect the plastic properties of soldered joints. This component is not taken into account by the proposed model, and its effect on reliability indicators of thermoelectric coolers requires further research and corresponding financial costs.

Opportunities. Additional opportunities for increasing reliability indicators of two-stage thermoelectric cooling devices consist in taking into account the geometry of thermoelements and the distribution of thermoelements in cascades (stages). This allows to optimize the design solutions to achieve the maximum values of temperature differences. With the introduction of elements of research data at enterprises, it becomes possible to lay products already at the design stage with enhanced reliability indicators.

Threats. Threats for practical use of the obtained results are connected with the expansion of the nomenclature of produced two-stage coolers tied to specific operating conditions. Therefore, this function should be incorporated into the algorithm of the automated system of design and manufacturing, which is the general trend of modern production. Additional costs are associated with the completion of the software product of the computer-aided design of thermoelectric coolers in the direction of accounting for the investigated reliability component.

Thus, SWOT analysis allows to assess the main directions of improving the design and manufacturing quality of two-stage thermoelectric cooling devices based on a reliability-oriented criterion. 


\section{Conclusions}

1. A model of the relationship between the reliability indices of two-stage TECs of various designs with the geometry of the branches of thermoelements in cascades (stages) in the $\Delta T_{\max }$ mode with electrical series of the cascades (stages) is proposed and analyzed. The obtained relationships enable to estimate the maximum cooling capacities and reliability indices of two-stage coolers of various designs.

2. The possibility of increasing the maximum temperature difference $\Delta T_{\max }$ to $4 \%$ is shown by choosing the optimal geometry of the branches of the thermoelements in the cascades (stages) $(l / S)_{1}>(l / S)_{2}$, which differs from the traditional $(l / S)_{1}=(l / S)_{2}$, at a given operating current. The proposed approach makes it possible to estimate the maximum cooling capacities of two-stage coolers and to optimize the design of systems for providing thermal regimes for radio electronic equipment.

\section{References}

1. Zebarjadi, M. Perspectives on thermoelectrics: from fundamentals to device applications [Text] / M. Zebarjadi, K. Esfarjani, M. S. Dresselhaus, Z. F. Ren, G. Chen // Energy \& Environmental Science. - 2012. - Vol. 5, № 1. - P. 5147-5162. doi:10.1039/c1ee02497c

2. Jurgensmeyer, A. L. High Efficiency Thermoelectric Devices Fabricated Using Quantum Well Confinement Techniques [Text] / A. L. Jurgensmeyer. - Colorado State University, 2011. $-54 \mathrm{p}$

3. Tsai, H.-L. Self-sufficient energy recycling of light emitter diode/thermoelectric generator module for its active-cooling application [Text] / H.-L. Tsai, P. T. Le // Energy Conversion and Management. - 2016. - Vol. 118. - P. 170-178. doi:10.1016/j.enconman.2016.03.077

4. Rowe, D. Materials, Preparation, and Characterization in Thermoelectrics [Text] / ed. by D. Rowe // Thermoelectrics and its Energy Harvesting, 2 Volume Set. - Boca Raton: CRC Press, 2012. - 544 p. doi:10.1201/b11891

5. Zaykov, V. Prediction of reliability on thermoelectric cooling devices [Text]. Book 1. Single-stage devices / V. Zaykov, L. Kirshova, V. Moiseev. - Odessa: Politehperiodika, 2009. - 120 p.

6. Zaykov, V. Prediction of reliability indices of a two-stage thermoelectric cooling device in the $\Delta T_{\max }$ mode [Text] $/ \mathrm{V}$. Zaykov, L. Kirshova, V. Moiseev, L. Kazanzhi // Technology and design in electronic equipment. - 2009. - № 4. - P. 45-47.

7. Zaykov, V. Prediction of reliability on thermoelectric cooling devices [Text]. Book 2. Cascade devices / V. Zaykov, V. Mescheryakov, Yu. Zhuravlov. - Odessa: Politehperiodika, 2016. $124 \mathrm{p}$

8. Brown, S. R. Yb 14 MnSb 11: New High Efficiency Thermoelectric Material for Power Generation [Text] / S. R. Brown, S. M. Kauzlarich, F. Gascoin, G. J. Snyder // Chemistry of Materials. - 2006. - Vol. 18, № 7. - P. 1873-1877. doi:10.1021/ cm060261t

9. Riffat, S. B. Improving the coefficient of performance of thermoelectric cooling systems [Text] / S. B. Riffat, X. Ma // International Journal of Energy Research. - 2004. - Vol. 28, № 9. - P. 753-768. doi:10.1002/er.991

10. Gromov, G. Obiemnye ili tonkoplenochnye termoelektricheskie moduli [Text] / G. Gromov // Komponenty i tehnologii. 2014. - № 9. - P. 38

11. Mischenko, A. S. Giant Electrocaloric Effect in Thin-Film PbZr0.95Ti0.05O3 [Text] / A. S. Mischenko // Science. 2006. - Vol. 311, № 5765. - P. 1270-1271. doi:10.1126/science. 1123811
12. Singh, R. Experimental Characterization of Thin Film Thermoelectric Materials and Film Deposition VIA Molecular Beam Epitaxial [Text] / R. Singh. - University of California, 2008. - 54 p.

13. Kruglyak, Yu. A. Landauer-Datta-Lundstrom Generalized Electron Transport Model [Text] / Yu. A. Kruglyak // Nanosystems, Nanomaterials, Nanotechnologies. - 2013. - Vol. 11 № 3. - P. 519-549.

14. Sootsman, J. R. New and Old Concepts in Thermoelectric Materials [Text] / J. R. Sootsman, D. Y. Chung, M. G. Kanatzidis // Angewandte Chemie International Edition. - 2009. Vol. 48, № 46. - P. 8616-8639. doi:10.1002/anie.200900598

15. Nesterov, S. B. Evaluation of the possibility of increasing the thermoelectric quality of nanostructured semiconductor materials for refrigeration equipment [Text] / S. B. Nesterov, A. I. Kholopkin // Refrigerating Technique. - 2014. - № 5. P. $40-43$

16. Gorskyi, P. Layered structure effects as realisation of anisotropy in magnetic, galvanomagnetic and thermoelectric phenomena [Text] / P. Gorskyi. - New York: Nova Publishers, 2014. Vol. XIV. - 352 p.

17. Sano, S. Development of high-efficiency thermoelectric power generation system [Text] / S. Sano, H. Mizukami, H. Kaibe // KOMATSU Technical Report. - 2003. - Vol. 49, № 152. P. $1-7$.

18. DiSalvo, F. J. Thermoelectric Cooling and Power Generation [Text] / F. J. DiSalvo // Science. - 1999. - Vol. 285, № 5428. P. 703-706. doi:10.1126/science. 285.5428 .703

19. Wereszczak, A. A. Thermoelectric Mechanical Reliability [Text]/ A. A. Wereszczak, H. Wang // Vehicle Technologies Annual Merit Reviewand Peer Evaluation Meeting. - Arlington, 2011. - $18 \mathrm{p}$.

20. Thermoelectric Cooler Reliability Report [Text]. - Melcor Corporation, 2002. - $36 \mathrm{p}$.

21. Choi, H.-S. Prediction of reliability on thermoelectric module through accelerated life test and Physics-of-failure [Text] / H.-S. Choi, W.-S. Seo, D.-K. Choi // Electronic Materials Letters. - 2011. - Vol. 7, № 3. - P. 271-275. doi:10.1007/ s13391-011-0917-x

\section{ОПРЕДЕЛЕНИЕ МАКСИМАЛЬНЫХ ОХЛАЖДАЮЩИХ ВОЗМОЖНОСТЕЙ ДВУХКАСКАДНЫХ ОХЛАДИТЕЛЕЙ ЛРИ ВАРИАЦИИ ГЕОМЕТРИИ ВЕТВЕЙ В КАСКАДАХ}

Рассмотрено влияние геометрии ветвей термоэлементов в каскадах на параметры и показатели надежности двухкаскадных термоэлектрических охладителей различных конструкций при последовательном электрическом соединении каскадов в режиме максимального перепада температуры. Получены соотношения для определения оптимальной геометрии ветвей термоэлементов в каскадах, соответствующей наибольшему значению перепада температуры для различных конструкций охладителей при заданном рабочем токе.

Ключевые слова: термоэлектрическое охлаждающее устройство, геометрия ветви термоэлементов, максимальный перепад температуры, конструкции охладителей.

Zaykov Vladimir, PhD, Chief of Sector, Research Institute «STORM», Odesa, Ukraine, e-mail: gradan@i.ua, ORCID ID: http://orcid.org/ 0000-0002-4078-3519

Mescheryakov Vladimir, Doctor of Technical Sciences, Professor, Head of the Department of Informatics, Odessa State Environmental University, Ukraine,e-mail: gradan@ua.fm,ORCID: http://orcid.org/ 0000-0003-0499-827X

Zhuravlov Yurii, PhD, Senior Lecturer, Department of Technology of Materials and Ship Repair, National University «Odessa Maritime Academy», Ukraine, ORCID: http://orcid.org/0000-0001-7342-1031 